\title{
Perceptions of teachers on creating space for code switching as a teaching strategy in second language teaching in the Eastern Cape province, South Africa
}

\begin{tabular}{|c|c|}
\hline \multicolumn{2}{|c|}{$\begin{array}{l}\text { Authors: } \\
\text { Sister L. Songxaba }{ }^{1} \\
\text { Adriaan Coetzer }^{2} \\
\text { Jacob M. Molepo }^{3}\end{array}$} \\
\hline \multicolumn{2}{|c|}{$\begin{array}{l}\text { Affiliations: } \\
{ }^{1} \text { Department of Continuing } \\
\text { Professional Teacher } \\
\text { Development (CPTD), Walter } \\
\text { Sisulu University, South Africa }\end{array}$} \\
\hline \multicolumn{2}{|c|}{$\begin{array}{l}{ }^{2} \text { Institutional Research and } \\
\text { Planning, Walter Sisulu } \\
\text { University, South Africa }\end{array}$} \\
\hline \multicolumn{2}{|c|}{$\begin{array}{l}{ }^{3} \text { Faculty of Educational } \\
\text { Sciences, Walter Sisulu } \\
\text { University, South Africa }\end{array}$} \\
\hline \multicolumn{2}{|c|}{$\begin{array}{l}\text { Corresponding author: } \\
\text { Sister Songxaba, } \\
\text { slsongxaba@gmail.com }\end{array}$} \\
\hline \multicolumn{2}{|c|}{$\begin{array}{l}\text { Dates: } \\
\text { Received: } 01 \text { June } 2017 \\
\text { Accepted: } 26 \text { Sept. } 2017 \\
\text { Published: } 08 \text { Dec. } 2017\end{array}$} \\
\hline \multicolumn{2}{|c|}{$\begin{array}{l}\text { How to cite this article: } \\
\text { Songxaba, S.L., Coetzer, A. \& } \\
\text { Molepo, J.M. 2017, } \\
\text { 'Perceptions of teachers on } \\
\text { creating space for code } \\
\text { switching as a teaching } \\
\text { strategy in second language } \\
\text { teaching in the Eastern Cape } \\
\text { province, South Africa', } \\
\text { Reading \& Writing } 8(1) \text {, a141. } \\
\text { https://doi.org/10.4102/ } \\
\text { rw.v8i1.141 }\end{array}$} \\
\hline \multicolumn{2}{|c|}{$\begin{array}{l}\text { Copyright: } \\
\text { (C) 2017. The Authors } \\
\text { Licensee: AOSIS. This } \\
\text { is licensed under the } \\
\text { Creative Commons } \\
\text { Attribution License. }\end{array}$} \\
\hline \multicolumn{2}{|l|}{ Read online: } \\
\hline 口p+a & $\begin{array}{l}\text { Scan this QR } \\
\text { code with your } \\
\text { smart phone or } \\
\text { mobile device } \\
\text { to read online. }\end{array}$ \\
\hline
\end{tabular}

This research reports on the findings regarding the perceptions of teachers towards creating space for the use of code switching as a teaching strategy in Afrikaans learning and teaching in the isiXhosa-speaking environments of the Transkei region. The aim of this investigation was to establish whether or not code switching can be used as a teaching strategy. A sample of 13 teachers from 12 schools was purposefully selected. A qualitative approach was used. Interviews and semi-structured questionnaires were used for data collection. The teachers admitted that they code switch during Afrikaans classes. It also transpired that teachers perceived code switching as the best way to facilitate understanding. The recommendations postulate a gradual move from a high tolerance of code switching in the lower classes to a low tolerance thereof in higher classes.

\section{Introduction}

There are 11 official languages in South Africa (SeSotho, Tswana, Swati, Venda, Tsonga, Afrikaans, English, Ndebele, Xhosa and Zulu) which, according to the Constitution of South Africa, enjoy equal status. This, however, is not so in the academic and corporate environments. English still plays a dominant role in these areas (Du Plessis 2014; Van der Walt 2009) and the indigenous languages are scarcely used or at most are included in a code-switched form in conversation or teaching (except when they are taught as subjects). This article seeks to investigate teachers' perceptions regarding the use of code switching (CS) as a teaching strategy in the teaching of Afrikaans second language in the Eastern Cape, where learners who speak isiXhosa as first language (L1) learn Afrikaans as a second language (L2) in a formal context. The speech accommodation theory of Giles (1971) underpins this article.

Scholars have approached CS from many different angles and have produced phonological, morphological, grammatical and societal perspectives on the phenomenon (Berthold, Mangubhai \& Batorowicz 1993; Myers-Scotton 1979; Šabec 1995). Only a few scholars have investigated the use of CS as an aid in teaching and learning Afrikaans. Scholars such as Rose and Van Dulm (2006) and Stone (1995) have made contributions to this field with their studies on English-Afrikaans CS in Western Cape classrooms, and on CS in sociolinguistic codes of the Afrikaans-speaking mixed-race community, respectively. No studies have been conducted in this field in the Eastern Cape. The main problem identified here is that in real-life situations, learners do code switch, but in the classroom, their CS is technically forbidden by the pre-1994 purist language policies, which maintain that only the target language should be used in the language classroom. Thus, while post-apartheid language policies (e.g. the language-in-education policy and the language policy for medium of instruction) give all 11 South African languages equal status, the mindset of many parents and teachers is still bound by the purist stance on language teaching. As such, they regard CS as 'language pollution' (Kamwangamalu 1989) and believe that CS leads to linguistic decay.

One of the features of the post-apartheid educational context of South Africa is that learners from various linguistic backgrounds are often intermingled in single classrooms. This calls for a reconsideration of the purist stance in L2 teaching (Mati 2004; Mhlawuli 2002), as monolingual L2 teaching poses comprehension challenges to non-mother tongue speakers of the target language (MacCabe 2013; Songxaba 2016). This article endeavoured to establish whether educators believe that CS can be used as a L2 teaching technique in the secondary schools of the Eastern Cape region of South Africa. As such, this article focuses on the use of CS for educational purposes. 


\section{Literature review}

There is a plethora of definitions assigned to CS, of which a few will be mentioned here. Gumperz (1982) defines CS as the juxtaposition of passages of speech belonging to two different grammatical structures or systems within the same conversation. According to Kamwangamalu (1992), Lehitse (1988), Myers-Scotton (1993a) and Numan and Carter (2001), CS is the alternating use of two or more linguistic varieties (languages, dialects of the same language or registers of the same language) at the word, phrase or clause, or sentence level in the course of a discourse. Scholars such as Shridar and Shridar (1980) and Singh and Sharma (2011) differentiate between CS and code mixing, in that they define code mixing as intra-sentential mixing (occurring within a single sentence at word, phrase or clause level) and CS as inter-sentential mixing, occurring between sentences in an extended stretch of discourse. For the purposes of this article, CS will be used as an umbrella term referring to all forms of language contact irrespective of the level of occurrence.

Research confirms that CS is a world-wide phenomenon, which occurs in various social and educational contexts (Madonsela 2016; Moodley 2010; Singh \& Sharma 2011; Shin 2010; Van der Walt 2009). Language scholars have different perceptions concerning the use of CS in teaching situations. Some scholars, such as Li (2008), Madonsela (2016), Moodley (2010) and Mahofa and Adendorf (2014), view CS in a positive light. They claim that CS has great potential for helping the bilingual teacher to achieve context-specific teaching and learning goals like clarifying difficult concepts and reinforcing a student's bilingual lexicon. Despite the positive arguments posited by the scholars above, some language scholars view CS in a negative light, arguing that CS is a sign of linguistic decay or a strategy to compensate for diminished proficiency, and the unsystematic result of not knowing at least one of the languages involved very well. Proponents of this viewpoint include Appel and Muysken (1987), Heredia and Brown (2009), Lyons (1968), Lawrence (1999), Romaine (1996) and $\mathrm{Li}$ (2008). The above contradicting notions are observable in the present research setting, where some teachers do not allow children to code switch because they view CS as a language impairment, while others see it as academic gain and happily incorporate it as a teaching strategy in their language classrooms.

Tonkin (2004) observes that languages are not contained in textbooks, but in the minds and on the lips of living people. As a result, languages change constantly in response to the pressures and demands of the social contexts in which they are used. The situation and the language groups that a speaker interacts with often influence his or her language choices, thus leading him or her to code switch so as to enhance mutual understanding. In agreement with this assertion, Finlayson and Slabbert (1997:128) cite an interviewee who said, 'When I speak with a Zulu, I speak Zulu, when I speak with a Tswana, Tswana and so when I speak with a person with one language I speak the language of him/her'. Because the classroom is a social setting where learners and teachers from various linguistic backgrounds interact, a challenge that presents itself to teachers is which languages to employ in the learning situation. Such decisions are often, as mentioned earlier, further complicated by the prescriptions of the language policies of South Africa.

The Language in Education Policy (LiEP) (1997) states clearly that in terms of the new Constitution of the Republic of South Africa, the government, and the Department of Education, recognise that our cultural diversity is a valuable national asset. Hence, these institutions are tasked, among other things, with the promotion of multilingualism, the development of the official languages and creating respect for all languages used in the country, including South African Sign Language. The standpoint of this policy confirms language equity and intends to dispel any tendency of undermining minority languages. Those who view CS in a positive light (Gough 1996; Vinson 2013; Van der Walt \& Kidd 2012) contend that language is a medium of communication and a vehicle to transfer cultural values and learning. Where one of the interlocutors is not fluent in the other language, his or her counterpart meets him or her halfway by means of CS. Though CS is not an independent language per se, in practice, it shares the same communicative values of all accepted and official languages, because it enables people (such as teachers and students) to understand one another. Furthermore, it does not seem probable that, in a multilingual environment, any one language can be free from the influence of others. To illustrate this, Mati (2004) argues that to a considerable extent, African language speakers experience the reality of the Western world as it has been conceptualised in English. He further explains that the conceptual web that English weaves around African language speakers leads to large-scale lexical influence, with CS being the norm rather than the exception, particularly in urban settings. The prevalence of CS in South Africa attests to a particularly close integration of English lexis into African languages.

In the language education classroom, difficulties and frustrations have been and are still being experienced in teaching Afrikaans second language. The problem lies with getting learners to speak 'suiwer Afrikaans' (pure Afrikaans). This refers to a type of Afrikaans that has no trace of CS, and which is spoken by mother tongue speakers of Afrikaans who have been introduced to the standard version of the language from a young age. This implies that, in the classroom, teachers are not allowed to include a word or sentence from another language other than the one being taught or the one that is a medium of instruction. Where purist language policies are enforced, Afrikaans classes are tense, and the learners speak in an artificial manner (compared to the spontaneous way in which they communicate with each other outside the class, where they freely mix the languages they understand) (Songxaba 2016:12-13). The main issue that this article seeks to explore is whether teachers believe CS can be used as a teaching or learning strategy in the teaching of Afrikaans second 
language, in order to create classroom environments that are more conducive to the learning of Afrikaans as an L2.

Having experienced how Afrikaans is taught as an L2 in the researched area, the researchers are aware of the frustration experienced by both teachers and learners when welldesigned teaching aids, gestures and facial expressions utilised in delivering lessons fail to yield the preconceived results because of a lack of a mutually understood lexicon. Sometimes, the language classroom situations demand the use of CS to enhance learner understanding of the language, but both learners and teachers are hindered by the fact that the assessment of learners does not allow trans-linguistic coding. The authors of this article feel that if the prevalence of a monolingual approach to the teaching of Afrikaans second language is not addressed, the L2 learners' performance in Afrikaans will continue to suffer because of the incongruence between classroom language realities (CS) and the purist assessment of learners' Afrikaans skills (e.g. questions set in Afrikaans only). This discrepancy is caused by the fact that the CS that takes place in the Afrikaans second language classroom is not yet provided for in the curriculum, even though the South African language policy is advocating for language equity. Afrikaans teachers use CS to facilitate teaching but in language assessment, on the other hand, no CS is allowed. This poses an academic dilemma for the learners because they answer incorrectly not because of lack of intellect but because they do not know certain Afrikaans words that are key to the question (MacCabe 2013:174). They end up guessing. If the question papers were set such that the difficult Afrikaans terms were translated in the home language or languages of the non-mother tongue learners of Afrikaans, the present situation would change.

The acceptance of CS is still problematic as it is not explicitly catered for in any curriculum-prescribed language teaching and learning methods. Probyn et al. (2002) found that despite the instruction of the LiEP that all schools should have a language policy, very few schools have language policies. This ignorance of schools and school governing bodies about language policies could lead to the maintenance of monolingual approaches to language teaching. The Language Policy for Medium of Instruction Document (1992:5) provides the relevant questions needed to address the above concerns. It highlights some important issues that need serious consideration in implementing the country's language policies. The need to address the policy implementation flaws is intended to prevent a situation in which language policy documents become mere white elephants.

The main question that comes to the fore in this line of reasoning is: How should CS be perceived in light of the language policy documents? Traditionally, the monolingual approach to language teaching and learning demanded strict adherence to the conventional grammatical rules of the target language to the total exclusion of the mother tongue. Concerning the rigidity of language teaching, Tonkin (2004) warns that:
Foreign language teachers, for their part, teach standard forms of language that may be far removed from the experience of many native speakers. They give little attention to non-standard forms. They may be right to do so, since their goal is to equip their students to succeed in an elite environment; but emphasis on standard forms may make it more difficult for their students to perceive the sheer diversity of linguistic expression and its function in the target society. In fact, their students may not fully understand what language is, and how it functions in society generally. (p. 1)

The above citation alerts language practitioners to the tendency of L2 teachers to subject their learners to a traditional approach of L2 language learning that could affect learners' acquisition of second languages negatively. In the present research setting, teachers are known to use CS in the process of teaching and learning Afrikaans to L2 learners, but the assessment of Afrikaans is only done via the standard form of the target language. Thus, a discrepancy exists between what prevails inside and outside the classroom (where CS is the norm). According to Foertsch (1998), the ways in which children communicate in their home cultures are critical to the development of written language models of reading and writing. He further argues that the home language of learners provides the foundation of the emergence of reading and writing behaviours and if there is a mismatch between the structures, values and expectations of the home language and school language, learners may be at a disadvantage for success in early reading tasks, and thus spend their entire school careers attempting to catch up. In line with this claim, Mahofa and Adendorf (2014:87) point out that the L1 of learners should be fully utilised in the learning and teaching of mathematics word problems. In the light of this assertion, the researchers believe that bilingual teaching, coupled with bilingual assessment, can alleviate the discrepancy described earlier.

This article seeks to contribute to our knowledge of the usefulness of CS as an appropriate teaching and learning strategy. In order to address the research problem, the following research questions were asked:

- What medium of instruction do teachers use in the teaching of Afrikaans second language?

- What opinions do teachers have about the use of CS in the classroom?

- To what extent do teachers allow CS during Afrikaans second language assessment?

- Can CS be used in the teaching of Afrikaans second language to assist learners?

The findings of this article might be useful for curriculum designers and material developers who prepare language materials for Afrikaans second language classrooms. It is also hoped that the findings of this research will not only create an appreciation of the challenges of teaching in an isiXhosaAfrikaans bilingual setting, but will also sensitise all stakeholders to deal with these challenges with empathy and understanding. Because CS is an international phenomenon (see Allen 2007; Shin 2010; Yousif 2012), this study might 
be relevant to other countries faced with similar bi- or multilingual teaching situations.

\section{Theoretical framework}

This research is underpinned by Giles's (1971) speech accommodation theory. He postulates the five important subcategories of speech accommodation, three of which were seen to be relevant to this research:

- having an awareness of what the addressee prefers and to switch accordingly

- establishing common ground to meet the addressee halfway with language

- employing measures to make yourself understood.

This theory underlies the present investigation. The question was whether or not the teaching situation was intending to meet the addressee (learners) halfway to assist them with their L2 learning, or just to satisfy the requirements of the curriculum, which in most instances uses assimilation approaches (Lemmer, Meyer \& Van Wyk 2012), disregarding the linguistic and educational needs of the learner.

\section{Methodology}

To fulfil the aim of the study, a qualitative approach was employed, which was, broadly speaking, based on the interpretive paradigm. Nieuwenhuis (2008:59-60) concludes that the ultimate aim of interpretivist research is to offer a perspective of a situation and to analyse the situation under investigation to provide insights into the way in which a particular group of people make sense of their situation or the phenomena they encounter. Here, the aim was to investigate and interpret the opinions of the teachers with regard to the use of CS as a teaching strategy and therefore the interpretive paradigm was deemed fit for this investigation.

\section{Sample}

The sample was drawn from a population of 59 Afrikaans teachers from the researched area. Forty-nine schools in the area offered Afrikaans as a subject. From this sample, 12 schools were selected - the choice of these schools was guided by the fact they were offering Afrikaans at all grade levels (Afrikaans second language was being phased out in the remaining schools, and was taught either in Grades 11 and 12 or in Grade 12 only). The participants consisted of 13 teachers purposefully selected from the 12 schools. The sample included teachers from remote rural areas as well as from schools in urban areas. Most Afrikaans teachers in the researched schools were L2 speakers of Afrikaans; the implication of this is that CS is unavoidable during lesson presentation, as the teachers' L1 was an African language.

\section{Research instrument, procedures and data analysis}

To solicit information from the participants, face-to-face interviews were conducted. The main focus of the teacher interviews was to establish from them whether they view
CS as a teaching strategy when teaching Afrikaans second language. Though it would have been advantageous to use single response questions owing to their easy processing, open-ended questions were included in order to probe more into the meanings the interviewees attached to their responses. At the same time, this enabled the researchers to see some behaviours such as gestures, expressions and mannerisms that could not have been revealed through single response questions. More important was the idea of interacting with the participants in their natural setting (which is the schools where they are teaching). This helped to ensure that the participants were at ease as they participated in the interviews (as opposed to the potentially threatening situation of a strange place). Researchers like McMillan (2008) attest to the benefits of this procedure when they point out that ' $t$ ]he setting influences the way humans behave and, therefore, it is not possible to understand the behaviour without taking into account the situational characteristics'. Each interview session took 30-35 min, and was video-taped for later analysis. The researchers also made field notes. After the completion of the interview process, the data were analysed.

The recorded field notes and video tapes of the responses from participants were transcribed and the data were coded. Following this, relevant themes emerged, which were further analysed in order to mine the data for information relevant to the research questions. Broadly speaking, the responses from the participants provided valuable background information against which CS can be used as a possible teaching aid. In what follows, the identified themes are outlined, with reference to some of the responses that led to the identification of these themes.

\section{Results}

\section{Teachers' opinions on code switching and on the value of mixing isiXhosa and Afrikaans in the teaching of Afrikaans}

All the teachers who participated in the study expressed positive opinions of CS in their Afrikaans lessons. They all approved of using CS as a teaching aid in the L2 language lesson. The participants' reaction to the question on the value of mixing languages in the teaching of Afrikaans was also quite unanimous. Eighty per cent of the respondents were of the opinion that CS assisted learners to understand better. These are verbatim responses in favour of CS by two participants:

The value of mixing isiXhosa and Afrikaans is increased understanding of lessons. [P12, Female, Teacher of Grade 11, Senior Secondary School G]

It facilitates learning. [P9, Female, Teacher of Grade 10, Senior Secondary School G]

However, some participants were of the view that CS did not necessarily improve communication skills. A Grade 8 teacher explained:

'There is no value in mixing languages, because this retards learning.' [P7, Female, Teacher of Grade 8, Senior Secondary School B] 
This was supported by another teacher:

'Mixing languages weakens the second language.' [P3, Male, Teacher of Grade 8, Senior Secondary School C]

\section{The use of Afrikaans as the only spoken language in Afrikaans classes}

To the interview question 'Is Afrikaans the only language that is spoken during Afrikaans lessons?', all participants admitted that they code switch to isiXhosa during Afrikaans lessons. The responses below are verbatim answers that were given by the participants.

A teacher from a senior secondary school answered:

Not at all. Mixing language is unavoidable. [P8, Female, Teacher of Grade 10, Senior Secondary School A]

This was echoed by a teacher from another secondary school who stated:

'If you only speak Afrikaans, you get nowhere with the lesson.' [P6, Male, Teacher of Grade 10, Senior Secondary School B]

The same sentiment was evident from the responses of the teachers from senior secondary schools. Both these teachers (Grade 10 and Grade 9) also said that CS was inevitable in the classroom:

'I have to translate, otherwise they do not understand.' [P11, Male, Teacher of Grade 10, Senior Secondary School D]

and

'Students struggle when you use Afrikaans only.' [P2, Female, Teacher of Grade 9, Senior Secondary School F]

In their responses, it also surfaced that monolingual teaching does not yield positive results in that learners struggle to understand the lesson when only Afrikaans is used but they understand better when the teachers code switch.

\section{Code switching in assessment}

When asked if CS was allowed in the assessment of Afrikaans second language (interview question 'Are the students allowed to code switch in the tasks and examinations?'), all participants stated that CS is not allowed in the assessment. This is indicative of inequalities in the teaching and learning situation. In the examinations, the non-mother tongue learners struggle to master the questions while their mother tongue counterparts do not experience this hardship. The following verbatim responses illustrate this stance:

'No, they are not allowed to code switch in the assessment.' [P10, Female, Teacher of Grade 11, Senior Secondary School C]

This was supported by another teacher, who pointed out:

'No. If they code switch, they are penalised.' [P4, Female, Teacher of Grade 9, Senior Secondary School D]

If CS is allowed in the teaching and learning scenario, why is it banned from assessment?

\section{Challenges faced by teachers in assessing Afrikaans}

The teachers in this sample explained that learners are not allowed to code switch in the assessment. This results in them failing the examinations. To this effect, a teacher remarked:

'The learners' answers display lack of understanding of the language in which the question is asked.' [P5, Male, Teacher of Grade 8, Senior Secondary School K]

Another teacher concurred:

'Their answers show lack of understanding of the question.' [P3, Female, Teacher of Grade 10, Senior Secondary School F]

This finding is in line with MacCabe's (2013:174) statement that L2 learners often fail because of numerous languagerelated problems, and not necessarily because of a lack of intellect. To the question seeking to establish ways in which the learners can be met halfway with Afrikaans during teaching and assessment, $55 \%$ of the participants suggested that CS should be employed in the primary school, secondary school and also in the first years of tertiary education until the students attain full mastery of the target language. In corroboration with this notion, Du Plessis (2014) says:

In reality some black first-year students at higher education institutions (HEIs) do not fully understand the concepts explained in class (in English); and do not have the level of fluency in English to express themselves clearly in tasks and assessments. (p. 1194)

\section{Discussion and conclusion}

The study sought to establish how teachers perceived the use of CS as a teaching strategy in the L2 classroom, where the L2 learners are L1 speakers of isiXhosa (on most counts). The teachers interviewed in this study answered with a unanimous ' $N o$ ' when asked whether they use only Afrikaans in the L2 classroom. Thus, there was clear evidence that teachers use CS to augment their teaching strategies. All the teachers in the sample stated that they code-switched in the Afrikaans L2 class, partly because of their own incompetence and partly because learners did not understand when only Afrikaans was spoken in the classroom.

While it transpired that the prevalent medium of instruction is some form of CS in the Afrikaans L2 classroom, it was clearly stated by educators that CS is not allowed in the assessment of Afrikaans second language. Rather, assessment takes place only in standard Afrikaans, which the learners fail because they do not understand the instructions and questions in the question paper. Ironically, the teachers were L2 speakers of Afrikaans too, and thus not equipped to teach learners the standard version of Afrikaans in which the assessment had to take place. The teachers pointed out that the reason for resorting to CS was to assist the learners to understand Afrikaans lessons. But what does it help to understand code-switched lessons when assessment maintains a purist stance? In this regard, the authors of this 


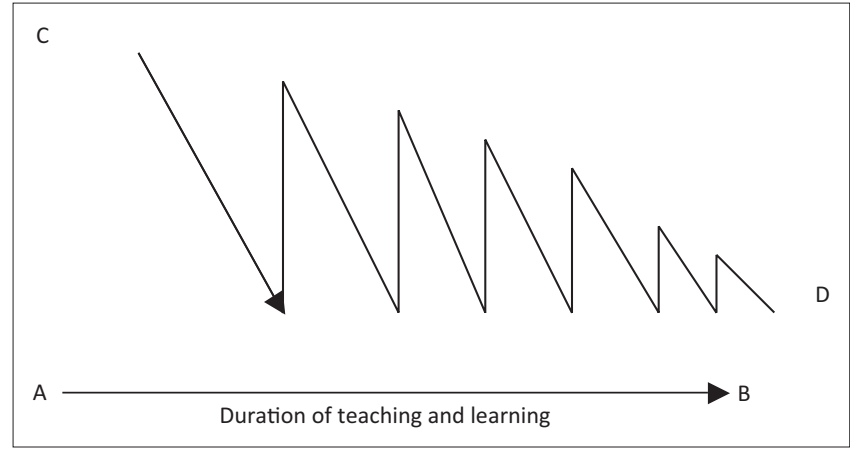

FIGURE 1: Gradual accommodation of code switching in Afrikaans second language.

article suggest that CS be infused as a teaching strategy not only to assist in the teaching of Afrikaans second language, but also to assist L2 learners to understand the target language and comprehend all questions in the assessment. We therefore recommend a gradual move from a high tolerance of CS (in lower classes) to a low tolerance of CS in higher classes. The diagram in Figure 1 suggests the manner in which this gradual accommodation of CS can be infused throughout the learning career of Afrikaans L2 learners.

Points A-B represent the duration of teaching and learning, which can be one teaching period, a week, a month or a year, or even the whole duration of learning over a period of years. Point C represents the spike of CS application and tolerance. Point D represents the least degree of CS application and tolerance. According to this figure, CS use and tolerance need to be high at the beginning of the learning cycle. The representation is based on the pedagogical principle of moving from the known to the unknown. The more the unknown is mastered, the more the known becomes redundant and is reduced, that is (in this context), the more Afrikaans is mastered, the less CS will be needed (adapted from Songxaba's, 2016:175-176, gradient accommodation model).

It became clear from this study that the subcategories of speech accommodation, first introduced by Giles in the 1970s, are still relevant today. In line with the predictions of speech accommodation theory, the teachers in this sample had a clear awareness and understanding of their leaners' communication needs, and they code-switched accordingly in the L2 language classroom, essentially because they knew that this was the only way to move forward in a lesson. Given that the teachers were also L2 speakers of Afrikaans, it is likely that they also employed CS to make themselves understood in class. The participants made clear efforts to meet their learners halfway in the language learning process, but this accommodation was only evident in the use of CS as a language teaching strategy. Because of existing language-in-education policies and curriculum expectations, learners' needs could not be accommodated (using CS) in any of the assessments that the L2 learners had to complete. Naturally, this study was limited by its small sample, and the results cannot be generalised to the larger population. Even so, the unanimous view of this sample of Afrikaans second language teachers in the Eastern Cape is that CS is the only way to get learners to understand content in the L2 classroom. This begs for further research into this field, particularly focusing on how CS could be incorporated in the curriculum in an accepted and 'standardised' way, not only as a teaching strategy but also as an aid in L2 language assessment.

The power dynamics at play depicted a gloomy picture of the plight of non-mother tongue learners in the Afrikaans classroom. The incongruence between the code-switched teaching and the monolingual assessment puts learners at a disadvantage. This state of affairs leads them to underperform, not because they do not have sufficient intellect, but because of a myriad of language problems (MacCabe 2013:174). This view is in line with Foertsch's (1998) contention that if there is a mismatch between the structures, values and expectations of the culture of the home language and the culture of the school or second language, learners may be at a disadvantage in early language tasks, such as early reading and writing, and thus they will spend their entire school careers attempting to catch up. Delpit (1988:280-298) concurs with this notion in his claim that it is particularly important for children of mixed race to be proficient at using the 'language of power'. This state of affairs inevitably leads to an unfortunate situation where the children of minority groups have to first assimilate the language and culture of the dominant group before they can smoothly progress in their academic careers. Thus, their use of the language is controlled by the power dynamics that are at play in the institution of learning and in the politics of the day. Mbatha and Plüddemann (2004) support this view when they say:

Despite the officialisation of isiXhosa and other African languages following the ushering in of the democratic dispensation in 1994 and the explicit promotion of multilingualism in the language-in-education policy for public schools, African languages continue to have a Cinderella status in education. (p. 5)

\section{Acknowledgements Competing interests}

The authors declare that they have no financial or personal relationships that may have inappropriately influenced them in writing this article.

\section{Authors' contributions}

S.L.S. was responsible for conceptualising the title of the article, writing the first draft of the article and effecting corrections from the reviewers and editors. A.C. contributed to the introduction, literature review and conclusion. J.M.M. contributed to the introduction and literature review.

\section{References}

Allen, S., 2007, 'The future of Inuktitut in the face of majority languages: Bilingualism or language shift?', Applied Psycholinguistic 28, 515-536. https://doi.org/10.1017/ S0142716407070282

Appel, R. \& Muysken, P., 1987, Language contact and bilingualism, Edward Arnold, London. 
Berthold, M., Mangubhai, F. \& Batorowicz, K., 1997, Bilingualism \& multilingualism Distance Education Centre, University of Southern Queensland, Toowoomba.

Delpit, L.D., 1988, 'The silenced dialogue: Power and pedagogy in educating other people's children', Harvard Educational Review 58(3), 280-298. https://doi. org/10.17763/haer.58.3.c43481778r528qw4

Du Plessis, S., 2014, 'Peer tutoring during language code-switching lectures as a teaching strategy in multilingual classes', SAJE 28(4), 1194-1215.

Finlayson, R. \& Slabbert, S., 1997a, 'I'll meet you halfway with language. Code switching functions within urban context', South African Journal of Linguistics 15(4), 123-134.

Foertsch, M., 1998, A study of reading practices, instruction, and achievement in district 31 schools, Oak Brook, viewed 10 June 2006, from http://www.ncrel.org/ sdrs/areas/31abs.htm

Giles, H., 1971, 'A study of speech patterns in social interaction: Accent evaluation and accent change', Unpublished PhD thesis, University of Bristol, UK.

Gumperz, J.J., 1982, Discourse strategies, Cambridge University Press, London.

Gough, D., 1996, 'Thinking in Xhosa and speaking in English: The theory and practice of contrastive analysis', Southern African Journal of Applied Language Studies 4(1), 2-19. https://doi.org/10.1080/10189203.1996.9724637

Heredia, R.R. \& Brown, J.M., 2009, Code switching, Texas International University pp. 1-5, viewed 10 July 2009, from http://www.tamiu.edu/ heredia/swtch. htm

Kamwangamalu, N., 1989, 'Code-mixing and modernisation', World Englishes 8(3), 321-332. https://doi.org/10.1111/j.1467-971X.1989.tb00672.x

Kamwangamalu, N.M., 1992, “"Mixes" and "Mixing": English across cultures', World Englishes 1(2-3), 173-181. https://doi.org/10.1111/j.1467-971X.1992 tb00062.x

Lawrence, D., 1999, 'Kodewisseling: Engels in Afrikaans - ' $n$ instrument tot effektiewe kommunikasie', SAALT Journal for Language Teaching 33, 265-274.

Lehitse, I., 1988, Lectures on language contact, MIT Press, London.

Lemmer, E.M., Meyer, C. \& Van Wyk, J.N., 2012, Multicultural education: A manual for the South African teacher, 2nd edn., Van Schaik Publishers, Pretoria.

Li, D., 2008, 'Understanding mixed code and classroom code-switching: Myths and realities', New Horizons in Education 56(3), 75-87.

Lyons, J., 1968, Introduction to linguistics, Cambridge University Press, London.

MacCabe, R., 2013, 'Scaffolded code-switching: A resource for achieving literacy', Journal for Language Teaching 47(2), 159-194. https://doi.org/10.4314/jlt. v47i2.9

Madonsela, S., 2016, 'The pedagogical enhancement of classroom interaction through the use of code switching in multilingual classrooms in South Africa', Journal of Educational Studies 15(1) 126-146.

Mahofa, E. \& Adendorf, S.A., 2014, 'Code switching in the learning of Mathematics word problems in Grade 10 , Journal of Educational Studies 13(2), 84-111.

Mati, X., 2004, 'Using code switching as a strategy for bilingual education in the classroom', paper presented at the 21st Annual AEAA Conference, 25-28 August, Human Sciences Research Council, Pretoria, pp. 1-14. http://repository.hsrc.ac $\mathrm{za} /$ bitstream/handle/20.500.11910/7523/1690.pdf?sequence $=1$

Mbatha, T. \& Plüddemann, P., 2004, The status of isiXhosa as an additional language in selected Cape Town secondary schools, published by Project for the Study of Alternative Education in South Africa (PRAESA) Occasional papers No. 18, Cape Town.
Moodley, V., 2010, 'Code switching and communicative competence in the language classroom', Journal for Language Teaching 44(1), 7-22.

McMillan, J.H., 2008, Educational research, 5th edn., Pearson, New York.

Mhlawuli, B., 2002, 'Sociolinguistic aspects of a bilingual's language use', PhD thesis, University of Port Elizabeth.

Myers-Scotton, C., 1993a, Social motivation for code switching, Clarendon Press, Oxford.

Myers-Scotton, C., 1993b, Duelling languages, Claredon Press, Oxford.

Myers-Scotton, C., 1979, 'Code switching as a "safe choice" in choosing a lingua franca', in W.C. McCormack \& S.A. Wurm (eds.), Language and society, pp. 71-87 Mouton and Co., The Hague.

Nieuwenhuis, J., 2008, 'Introducing qualitative research', in K. Maree (ed.), First steps in research, pp. 47-68, Van Schaik, Pretoria.

Numan, D. \& Carter, D., 2001, Teaching English to speakers of other languages, Cambridge University Press, Cambridge.

Probyn, M., Murray, S., Botha, L., Botya, P., Brooks, M. \& Westphal, V., 2002, 'Mindin the gaps - An investigation into language policy and practice in four Eastern Cape districts', Perspectives in Education 20(1), 29-46.

Romaine, S., 1996, 'Bilingualism', in W.C. Ritchie \& T.K. Bhatia (eds.), Handbook of second language acquisition, pp. 147-168, Academic Press, San Diego, CA.

Rose, S. \& Van Dulm, O., 2006, 'Functions of code switching in multilingual classrooms', Per Linguam 22(2), 1-13.

Šabec, N., 1995, Half pa pu: The Language of Slovene American, Studia Humanitatis, Ljublijana, ŠKUC.

Shin, S., 2010, 'The functions of code-switching in Korean Sunday school', Heritage Language Journal 7(1), 91-116.

Shridar, S.N. \& Shridar, K.K., 1980, 'The syntax and psycholinguistics of bilingual code mixing', Canadian Journal of Psychology 34(4), 407-416. https://doi.org/10.1037/ h0081105

Singh, R. \& Sharma, G. (eds.), 2011, Annual review of South Asian languages and linguistics, De Gruyter Mouton, Berlin.

Songxaba, S.L., 2016, The use of Afrikaans-English-Xhosa code switching in the classroom, Scholars' Press, Saarbrücken, Germany.

Stone, G., 1995, 'The lexicon and sociolinguistic codes of the working-class Afrikaansspeaking Cape Peninsula coloured community', in R. Mesthrie (ed.), Language and social history. Studies in South African sociolinguistics, pp. 277-290, David Phillips, Cape Town.

The Language Policies for Medium of Instruction Document, 1992, 'Language Policies for Medium of Instruction: An information document for discussion by parents, teachers and principals', ETIC Reporter 16(2\&3) 4-16.

Tonkin, H., 2004, 'Language and society', Issues in Global Education 178, 1-24.

Van der Walt, C., 2009, 'The function of code switching in English language learning classes', Per Liguam 25(1), 30-43.

Van der Walt, L. \& Kidd, M., 2012, 'Acknowledging biliteracy in higher education assessment strategies: A tale of two trials', in D. Aintzane, D. Lagasabaster \& J.M. Sierra (eds.), English-Medium Instruction at Universities, Multilingual Matters, Bristol, UK.

Vinson, J., 2013, Why translanguaging is the future!, viewed 05 May 2013, from $\mathrm{http}: / /$ bilingualeducationtranslanguaging.bravesites.com

Yousif, J.D., 2012, 'Code switching and code mixing: A case study of child bilingualism in Iraq', Journal of the College of Arts University of Basrah 62, 48-63. 